\title{
Pancreatic Neuroendocrine Tumour- An Interesting Case Report
}

\author{
Sneha $\mathrm{M}^{1}$, Swarna Sri ${ }^{2}$, Anunayi J. ${ }^{3}$ \\ ${ }^{1}$ Department of Pathology, Osmania Medical College, Koti, Hyderabad, Telangana, India. \\ 2Department of Pathology, Osmania Medical College, Koti, Hyderabad, Telangana, India. \\ ${ }^{3}$ Department of Pathology, Osmania Medical College, Koti, Hyderabad, Telangana, India.
}

\section{INTRODUCTION}

Neuroendocrine neoplasms of the pancreas are moderately uncommon, representing roughly $1-2 \%$ of every pancreatic neoplasm, and are composed of epithelial neoplastic cells with neuroendocrine differentiation. Neuroendocrine neoplasms are potentially malignant including well-differentiated types and poorly differentiated types. We present a case report of a 40 -year-old female patient with complaints of pain abdomen after consumption of food and loss of weight and appetite over a period of three months with a diagnosis of pancreatic neuroendocrine tumour made based on histopathology.

\section{PRESENTATION OF CASE}

\section{History and Examination}

A 40 year old female patient presented with dull aching pain in the upper abdomen since 3 months which increased in intensity after consumption of food and h/o pain radiating to the back was present. History of loss of weight and loss of appetite was present. On per abdomen examination, except for tenderness on palpation in the epigastric region, rest of examination was normal.

\section{Investigations}

Chromogranin A - $258 \mathrm{ng} / \mathrm{mL}$ :

Gastrin - $72 \mathrm{pg} / \mathrm{mL}$ :

Serum Lipase $-34 \mathrm{U} / \mathrm{L}$ :

Serum Amylase - $112 \mathrm{U} / \mathrm{L}$ :

Serum Glucose- $695 \mathrm{mg} / \mathrm{dl}$, HbA1c -5.9\%: Normal Range - 4-5.6\%.

\section{CBP}

Normocytic Hypochromic anaemia with neutrophilic leucocytosis.

\section{USG Abdomen and Pelvis}

Space occupying lesion in head of pancreas seen as a well-defined hyper echoic lesion measuring $2.5^{*} 4 \mathrm{~cm}$ with no increase in vascularity.

\section{Upper GI Endoscopy}

Non circumferential ulcerated exophytic growth noted along medial wall of D1 with scope negotiated beyond with moderate resistance.

\author{
Normal levels $-<100 \mathrm{ng} / \mathrm{mL}$ \\ Normal levels (fasting) - 13 to $115 \mathrm{pg} / \mathrm{mL}$ \\ Normal Range - $<60 \mathrm{U} / \mathrm{L}$ \\ Normal Range - 25-125 U/L
}

Corresponding Author:

Dr. Sneha $M$,

Flat No. 202, SLN Arcade-2,

Plot No. 14, Haripuri Colony,

Road No. 5, Kothapet,

Hyderabad, Telangana, India.

E-mail: snehamed10@gmail.com

DOI: $10.14260 / \mathrm{jemds} / 2020 / 344$

Financial or Other Competing Interests: None.

How to Cite This Article:

Sneha M, Sri S, Anunayi J. Pancreatic neuroendocrine tumour- an interesting case report. J. Evolution Med. Dent. Sci. 2020;9(19):1575-1578, DOI:
Submission 09-08-2019, Peer Review 12-01-2020, Acceptance 18-01-2020, Published 11-05-2020.

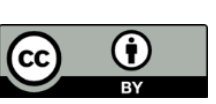




\section{CT Abdomen Plain and with Contrast}

Evidence of heterogeneously enhancing soft tissue density mass lesion noted in close approximation of head of pancreas measuring $4 * 3 * 3 \mathrm{cms}$ with areas of hypo density noted suggestive of necrosis along with sub-centric lymphadenopathy seen at lesser omentum, splenic hilum and mesentery.

\section{Gross Examination}

Received grey brown soft tissue mass measuring $16 * 12 * 5 \mathrm{~cm}-$ consisting of distal stomach, duodenum, spleen and pancreas with mass near the head measuring $8 * 5 * 3 \mathrm{~cm}$. Received single grey white to grey brown soft tissue mass measuring $0.3 \mathrm{cc}$.Biopsy near common hepatic artery.
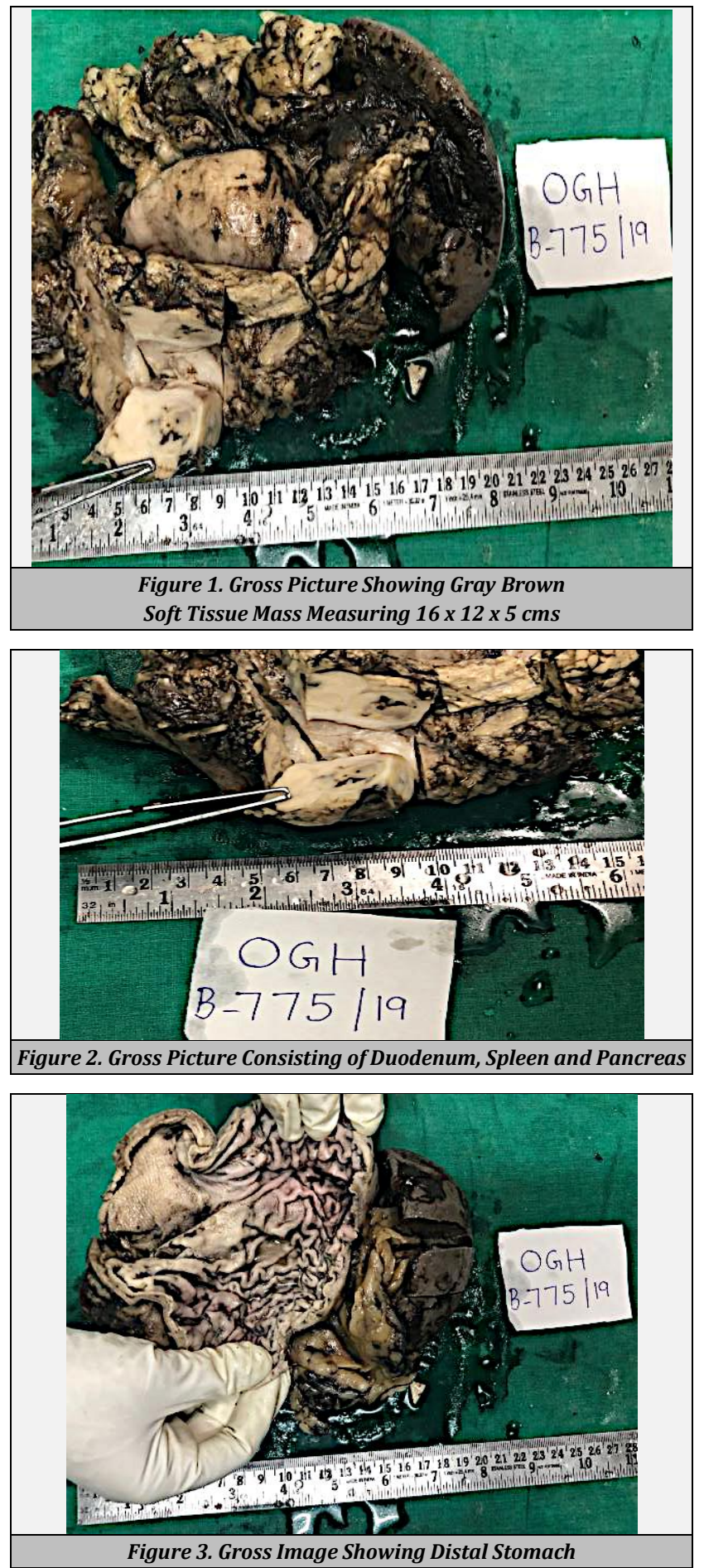

\section{Microscopic Examination}

Multiple sections studied from the Whipple pancreaticoduodenectomy showed tumour tissue in the pancreas with the features of well differentiated neuro endocrine tumour. Lymphovascular emboli also seen. Mitotic activity is 2-3/10 HPF. Tumour tissue is arranged in organoid architecture: insular pattern, trabecular pattern. Individual cells are round to oval, with moderate amount of amphophilic and finely granular cytoplasm, nuclei are central, round to oval with 'salt and pepper' chromatin. Tumour is seen infiltrating the duodenal wall. Proximal margin and distal margin are free from tumour, sections from spleen show congestive changes. Sections from biopsy taken near common hepatic artery shows reactive hyperplasia in the lymph node.
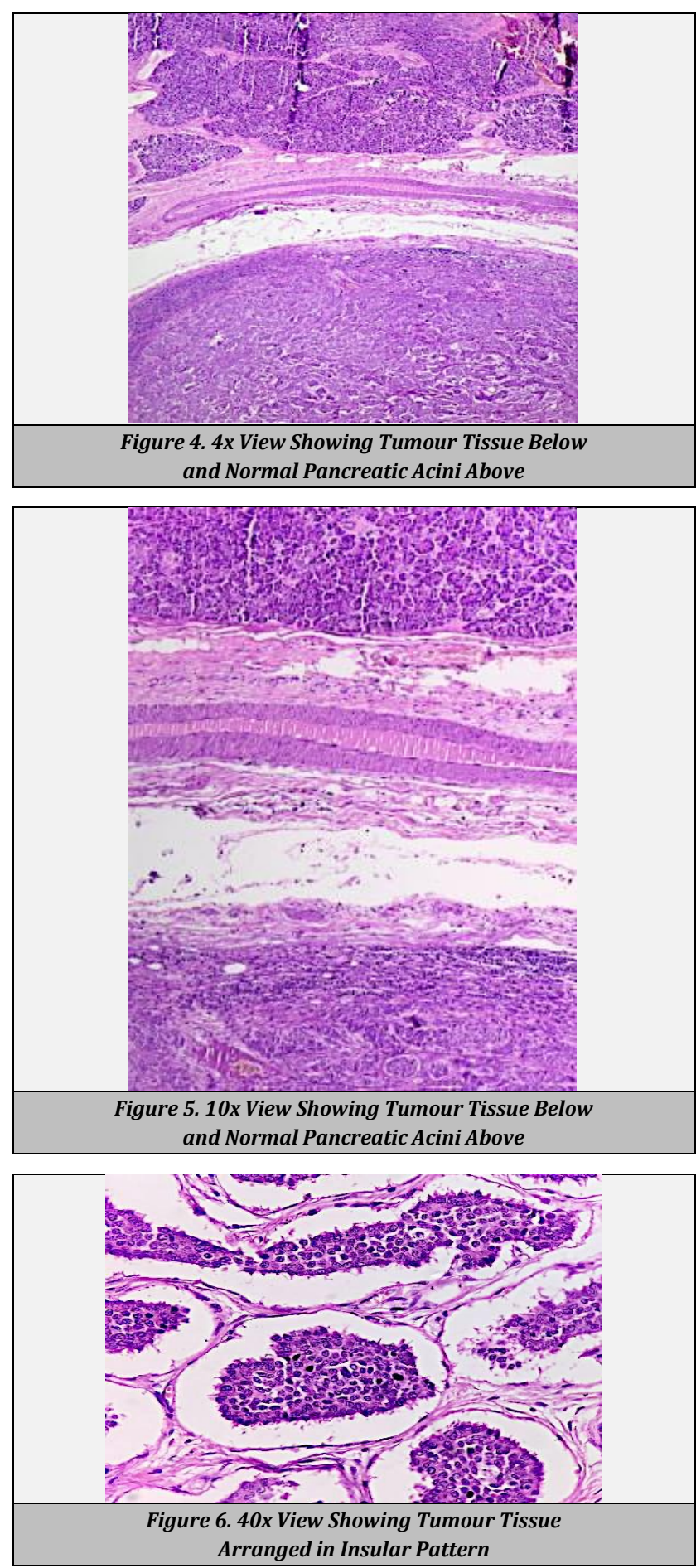

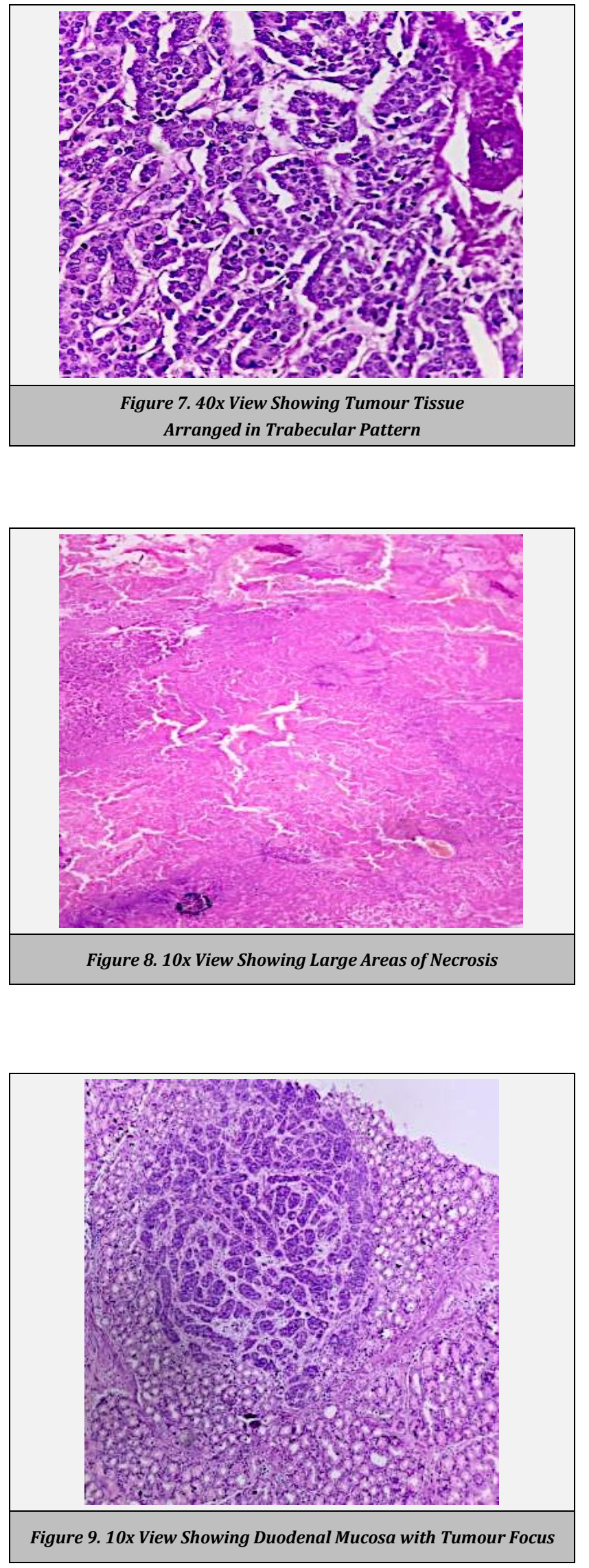

Immunohistochemistry

Strongly positive for Chromogranin and Synaptophysin

\section{DISCUSSION}

Patients with NETs are ordinarily from 30 to 60 years of age, and show no significant gender predilection.

\section{Histologic Grading and Classification ${ }^{1}$}

2017 WHO Classification of Endocrine Organs.

\section{Well Differentiated NENs}

- $\quad$ NET G1: Mitotic Index $<2 / 10 \mathrm{HPF}, \mathrm{Ki} 67$ Index $<3 \%$

- $\quad$ NET G2: Mitotic Index 2-20/10 HPF, Ki67 Index 3-20\%

- NET G3: Mitotic Index $>20 / 10$ HPF, Ki67 Index $>20 \%$

\section{Poorly Differentiated NENs}

- NEC G3: Mitotic Index $>20 / 10$ HPF, Ki67 Index $>20 \%$

- Small cell type.

- $\quad$ Large cell type.

Mixed neuro endocrine non-neuroendocrine neoplasm (MiNEN)

\section{Immunohistochemistry}

Diagnostic Markers2: Well differentiated NENs are characterized by the presence of cytoplasmic neuroendocrine granules. At present acceptable reliable markers are synaptophysin and chromogranin. Well-differentiated NENs will in general show stronger and more diffuse staining with CD56 antibody, against neural cell adhesion molecules, is less specific as a neuroendocrine marker. Around $45 \%$ of sporadic well differentiated NENs show loss of expression of DAXX and ATRX immunohistochemically.

\section{DIFFERENTIAL DIAGNOSIS}

In primary pancreatic neoplasms, Acinar Cell Carcinoma (ACC) should initially be precluded in light of the fact that their radiologic/macroscopic and microscopic morphology simulates NETs ${ }^{2}$. Both neuroendocrine and acinar cell markers (Trypsin and BCL10) together aids in distinguishing these two lesions.

Solid Pseudopapillary Neoplasms (SPNs) also simulates NETs. Immunohistochemical atomic recolouring of betacatenin is extremely valuable to analyse it as a SPN. Recognizing from a blended acinar-neuroendocrine carcinoma might be testing.

Metastatic clear cell carcinomas simulates Clear cell variant of NET while Oncocytic variation of NET may look like hepatocellular carcinoma.

\section{Treatment and Prognosis}

Complete resection of the tumour is a lone therapeutic treatment for low grade NETs (NET G1 or G2). Untreated pancreatic NETs metastasize to the liver. Most PNETs are inactive yet have malignant potential. 


\section{REFERENCES}

[1] Lloyd RV, Osamura RY, Kloppel G, et al. WHO Classification of Tumours of Endocrine Organs (World Health Organization Classification of Tumors). $4^{\text {th }}$ edn. Lyons France: IARC Press 2017.
[2] Fukushima N. Neuroendocrine neoplasms of the pancreas: the pathological viewpoint. JOP: J Pancreas (Online) 2018;S(3):328-34. 